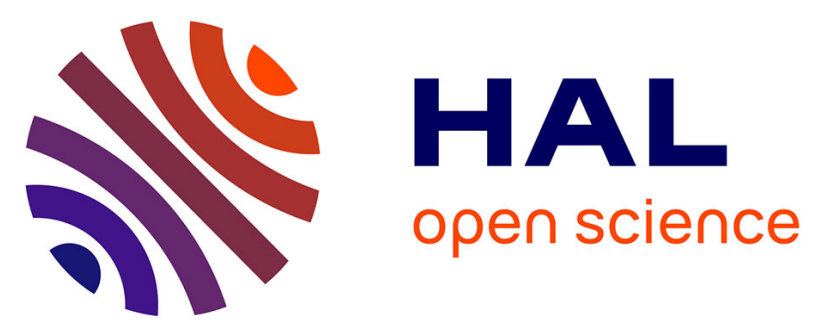

\title{
Association between cellular HIV-1 DNA level and mortality in HIV-1 infected African adults starting ART with high CD4 counts
}

Jean-Baptiste N'Takpe, Delphine Gabillard, Raoul Moh, E. Gardiennet, Arlette Emiene, Anani Dodzi Badje, Menan Gerard Kouame, Thomas-d'Aquin Toni, Sophie Karcher, Jérôme Le Carrou, et al.

\section{To cite this version:}

Jean-Baptiste N'Takpe, Delphine Gabillard, Raoul Moh, E. Gardiennet, Arlette Emiene, et al.. Association between cellular HIV-1 DNA level and mortality in HIV-1 infected African adults starting ART with high CD4 counts. EBioMedicine, 2020, 56, pp.102815. 10.1016/j.ebiom.2020.102815 . hal-03135051

\section{HAL Id: hal-03135051 \\ https://hal.science/hal-03135051}

Submitted on 8 Feb 2021

HAL is a multi-disciplinary open access archive for the deposit and dissemination of scientific research documents, whether they are published or not. The documents may come from teaching and research institutions in France or abroad, or from public or private research centers.
L'archive ouverte pluridisciplinaire HAL, est destinée au dépôt et à la diffusion de documents scientifiques de niveau recherche, publiés ou non, émanant des établissements d'enseignement et de recherche français ou étrangers, des laboratoires publics ou privés.

\section{(ㅇ)(1) $\$$}

Distributed under a Creative Commons Attribution - NonCommercial - NoDerivatives $\mid 4.0$ 
Research paper

\title{
Association between cellular HIV-1 DNA level and mortality in HIV-1 infected African adults starting ART with high CD4 counts
}

\author{
Jean Baptiste N'takpe ${ }^{\mathrm{a}, \mathrm{b}, 1, *}$, Delphine Gabillard ${ }^{\mathrm{a}, \mathrm{b}, 1}$, Raoul Moh ${ }^{\mathrm{a}, \mathrm{b}, \mathrm{c}}$, Elise Gardiennet $^{\mathrm{d}}$, \\ Arlette Emieme ${ }^{\mathrm{a}, \mathrm{b}, \mathrm{e}}$, Anani Badje ${ }^{\mathrm{a}, \mathrm{b}}$, Gérard M. Kouame ${ }^{\mathrm{a}, \mathrm{b}}$, Thomas-d'Aquin Toni ${ }^{\mathrm{a}, \mathrm{b}, \mathrm{e}}$, \\ Sophie Karcher ${ }^{\mathrm{a}, \mathrm{b}}$, Jérome Le Carrou ${ }^{\mathrm{a}, \mathrm{b}}$, Hervé Ménan ${ }^{\mathrm{a}, \mathrm{b}, \mathrm{e}}$, Christine Danel $^{\mathrm{a}, \mathrm{b}}$, Serge P. Eholie ${ }^{\mathrm{a}, \mathrm{b}, \mathrm{c}}$, \\ Christine Rouzioux ${ }^{\mathrm{b}, \mathrm{d}, 1}$, Xavier Anglaret $^{\mathrm{a}, \mathrm{b}, 1}$ \\ ${ }^{a}$ Centre Inserm 1219, Institut de Recherche pour le Développement(IRD), University of Bordeaux, 146 rue Léo Saignat, 33076 Bordeaux, France \\ ${ }^{\mathrm{b}}$ PACCI/ANRS research site in Côte d'Ivoire, Côte d'Ivoire \\ ' Département de Dermatologie et Maladies Infectieuses, Université Felix Houphouët Boigny, Abidjan, Côte d'Ivoire \\ ${ }^{d}$ AP-HP, CHU Necker Enfants Malades, EA 7327 Université Paris Descartes, Paris, France \\ e CeDReS, CHU de Treichville, Abidjan, Côte d'Ivoire
}

\section{A R T I C L E I N F O}

\section{Article History:}

Received 31 March 2020

Revised 12 May 2020

Accepted 13 May 2020

Available online 5 June 2020

\section{Keywords:}

HIV-1 DNA

Adults African

ART

Pronostic

Mortality

\section{A B S T R A C T}

Background: High HIV-1 DNA levels in peripheral blood mononuclear cells (PBMC) were associated with a higher risk of severe morbidity and a faster decline in CD4 count in ART-naive patients. We report the association between HIV-1 DNA and mortality in HIV-infected adults in a trial of early ART in West Africa.

Methods: In the Temprano trial, HIV-infected adults were randomly assigned to start ART immediately or defer ART. After trial termination, HIV-1 DNA was measured in whole blood samples frozen at baseline. We analyzed the association between baseline PBMC HIV-1 DNA and long-term mortality.

Findings: 2019 patients were followed for 9253 patient-years (median 4.9 years). At baseline, the median CD4 count was $462 / \mathrm{mm}^{3}$ [IQR 368-571], the median plasma HIV-1 RNA $4.7 \log _{10}$ copies/ml [IQR 4.0-5.2], and the median HIV-1 DNA $2.9 \log _{10}$ copies/million PBMC [IQR 2.5-3.3]. During follow-up, 86 participants died. In univariate analysis, the hazard ratio [HR] of death was 2.67 (95\% CI, 1.68-4.22) for patients with HIV-1 DNA $\geq 3 \log _{10}$ copies/million PBMC vs. others, and 2.10 (95\% CI, 1.38-3.21) for patients with HIV-1 RNA $\geq 5$ $\log 10$ copies/ml vs. others. In multivariate Cox regression analysis, HIV-1 DNA levels $\geq 3 \log _{10}$ copies/million PBMC were strongly associated mortality (adjusted HR $=2.09,95 \% \mathrm{CI} 1.24-3.52, p=0.005$ ) while the association between baseline plasma HIV-1 RNA and mortality was not significant.

Interpretation: In these African adults who started ART with high CD4 counts, HIV-1 DNA was a strong independent predictor of death. The HIV reservoir still plays a prognostic role in the early ART era.

Funding: This trial was supported by the French National Agency for AIDS and viral hepatitis research (ANRS, Paris, France; Grants ANRS 12136, 12224 and 12253)

(c) 2020 The Author(s). Published by Elsevier B.V. This is an open access article under the CC BY-NC-ND license. (http://creativecommons.org/licenses/by-nc-nd/4.0/)

\section{Introduction}

The persistence of the Human Immune deficiency Virus (HIV) in reservoirs is a obstacle to its eradication [1,2]. The reservoir of infected cells is established very early and then influences the evolution of the disease [3]. HIV-1 DNA level in Peripheral Blood Mononuclear Cells (PBMC) is a proxy for reservoir size [4,5]. Previous studies

\footnotetext{
* Corresponding author at: Centre Inserm 1219, Institut de Recherche pour le Développement (IRD), University of Bordeaux, 146 rue Léo Saignat, 33076 Bordeaux France.

E-mail address: jean-baptiste.ntakpe@u-bordeaux.fr (J.B. N'takpe).

1 These authors contributed equally to this manuscript.
}

show that HIV-1 DNA predicts HIV disease progression in untreated subjects, therapeutic success in people on antiretroviral therapy (ARV), and virologic rebound in subjects with treatment failure, all of this independently of CD4 count and plasma HIV-1 RNA level [6-9]. These studies were mainly cohorts conducted in industrialized countries with relatively small numbers of participants, and before the WHO recommendation that all HIV-infected individuals should be treated regardless of their clinical, immunological or virological status [10-12].

We conducted the Temprano trial between 2008 and 2015. Temprano was a randomized controlled trial evaluating the benefits and risks of early ART and isoniazid preventive therapy (IPT) in HIV- 


\section{RESEARCH IN CONTEXT}

\section{Evidence before this study}

We searched PubMed with search terms "HIV-1 DNA [Title] AND (clinical OR Prognosis or death), on July 31, 2019, for articled published in English. There were no date restrictions. Before this study, evidence from cohort studies suggested that HIV-1 DNA predicts HIV disease progression in untreated subjects, therapeutic success or failure in people on antiretroviral therapy (ARV), and virologic rebound in subjects with treatment failure, all of this independently of CD4 count and plasma HIV-1 RNA level. These studies were conducted before WHO recommended that all HIV-infected individuals should start ART regardless of their clinical, immunological or virological status.

\section{Added value of this study}

We analyzed the association between HIV-1 DNA in PBMC and long-term mortality in African adults who started ART early. We found that patients with high HIV-1 DNA level at baseline had a higher 6-year mortality risk than other patients, irrespective of plasma viral load, CD4 cell count and ART. This is the first study to report this association. Previous cohort studies conducted in industrialized countries with shorter follow-ups have shown that high DNA levels are closely associated with the prognosis, using an outcome combining severe morbidity, mortality and CD4 cell count evolution. This study also help put into perspective the practical utility of cellular HIV-1 DNA and plasma HIV-1 RNA in clinical monitoring. Even if baseline HIV-1 DNA and RNA levels were significantly correlated, the correlation had a poor coefficient, suggesting a different role for these two markers in the pathophysiology of HIV-1 infection. The association observed in univariate analysis between pre-therapeutic plasma HIV-1 RNA and mortality was quashed by the effect of cellular HIV-1 DNA in multivariate analysis, which suggests that infected cells play a major role in the progression of the disease. Therefore, with regard to pre-therapeutic markers, HIV-1 DNA seems to be a better predictor of the long-term prognosis. In terms of on-treatment markers though, HIV-RNA is the gold standard for monitoring ART efficacy.

\section{Implications of all the available evidence}

The reservoir of HIV-1 continues to play a key role in the prognosis in patients who start ART early, regardless of plasma viral load. Cellular HIV-1 DNA is an interesting clinical marker for use in future research. At present, the pre-therapeutic level of DNA can be used as a predictor of treatment success. In the future, the evolution of HIV-1 DNA under treatment may become attractive for comparing new strategies with effective reservoir action.

infected West African adults with high CD4 counts. The participants were followed for 30 months and the primary endpoint was severe morbidity [10]. At the end of the 30-month follow-up, each patient was invited to participate in a prolonged post-trial follow-up until the last patient in Temprano had completed the 30 months of followup (January 2015). The endpoint of the post-trial phase was mortality [13].

In the present article, we look for an association between HIV-1 DNA levels in PBMC and long-term mortality in HIV-infected adults who participated in Temprano.

\section{Methods}

\subsection{Temprano trial}

Temprano was a $2 \times 2$ factorial RCT conducted in Côte d'Ivoire. The trial design and results have been reported previously [10]. In summary: the inclusion criteria were HIV infection, age $\geq 18$ years, CD4 count $\leq 800 / \mathrm{mm}^{3}$ and no criteria for starting ART according to the most recent WHO guidelines. Participants were randomized into one of four arms: Arm-1 ('Deferred-ART'), in which ART was deferred until the WHO criteria for starting ART were met; Arm-2 ('DeferredART+IPT'), in which ART was deferred and a 6-month IPT was prescribed; Arm-3 ('Immediate-ART'), in which ART was started immediately; Arm-4 ('Immediate -ART+IPT'), in which ART was started immediately and a 6-month IPT was prescribed.

After randomization, all participants had a series of blood tests including CD4 count and plasma HIV-1 RNA. Plasma and whole blood samples were also frozen at $-80{ }^{\circ} \mathrm{C}$. All participants were followed for 30 months. The primary endpoint was severe morbidity, defined as a combination of all-cause deaths, AIDS diseases, non-AIDS malignancies and non-AIDS-invasive bacterial diseases. The main results of the Temprano trial at month 30 were that early ART and IPT both reduced severe morbidity significantly [10].

\subsection{Post-trial phase}

The first Temprano participant completed 30 months of follow-up in September 2010. From this date on, it was suggested to all patients who reached their 30-month visit that they continue to be followed in a post-trial phase until the last patient had completed the 30 months of follow-up specified for the trial [13].

Temprano and the post-trial phase had similar procedures. In the post-trial phase, as in Temprano: patients made quarterly visits to their care center; CD4 count and plasma HIV-1 RNA were measured every six months; CD4 count, viral load and antiretroviral drugs were supplied free of charge; patients who did not attend for a trial appointment were traced by experienced social workers. Patients followed in the post-trial phase were subject to the same rules regarding ART prescription as those who were still being followed for the trial in the same calendar period. Patients assigned to the Deferred-ART strategy started ART when they reached the most recent WHO criteria for starting ART, during the trial if these criteria were met $<30$ months after enrolment, or during the post-trial phase if the criteria were met $>30$ months after enrolment. Patients who did not reach these criteria before the closing date never started ART, either during the trial or in the post-trial phase. Death assessment procedures were exactly the same during the trial and post-trial phases, including verification of evidence of death by an event documentation committee. However, access to care and treatment other than ART differed between the trial and post-trial phases. In case of a morbidity event in the trial phase, transportation for unscheduled visits, investigations, hospital admission, and non-antiretroviral drugs were free of charge. In the post-trial phase, patients had to pay for tests and treatment, just as any other patient followed up in routine condition in the same care center. Due to these differences, the validation of diagnoses by the Event Documentation Committee was limited to the trial phase.

\subsection{HIV-1 DNA measurement}

PBMC HIV-1 DNA levels were measured on whole blood samples frozen at baseline. The HIV-1 DNA real time PCR was performed in the laboratory of virology at the Necker University Hospital in Paris. The technique was based on the amplification of the Long Terminal Repeat (LTR) gene well adapted to HIV-1 non B sutypes and referring to the 8E5 cell line containing one HIV copy per cell (HIV DNA cell, Biocentric, Bandol, France) [14]. The threshold of the technique was 5 
copies of HIV-1 DNA per PCR well. The HIV-1 DNA load was expressed as a proportion of infected cells among the target cells. Results were expressed as the HIV-1 DNA $\log _{10}$ copy number per million PBMC [3,5]. HIV1 RNA levels were measured using the Biocentric assay as previously reported [10].

\subsection{Statistical analysis}

We used the Kaplan-Meir method to estimate the cumulative probability of death. Mortality rates were estimated by dividing the number of deaths by the cumulative person time at risk. The time at risk started at randomization and ended on January 5, 2015. Follow-up data were censored when participants died or were lost to follow-up. Patients were defined as lost-to-follow-up if they did not attend their last scheduled appointment and no further information on their vital status was available within the 6 months preceding the closing date of the database.

Cox proportional hazards models were used to look for an association between baseline PBMC HIV-1 DNA level and mortality by the end of the post-trial phase, adjusting the Hazard Ratio for the trial strategies (Early-ART vs. Deferred-ART; IPT vs. no-IPT), baseline CD4 cell count, baseline plasma HIV-1 RNA level, age, sex, and trial center (as a random effect). We refer to trial 'strategies' whenever data combining patients assigned to 'IPT' (arm-2-and-4), 'No-IPT' (arm-1-and-3), 'Early-ART' (arm-3-and-4) and 'Deferred-ART' (arm-1-and-2) is given.

We then carried out two sensitivity analyses: (i) we replaced adjustment for Early vs. Deferred ART trial strategy with adjustment for actual ART initiation as a time-dependent variable; (ii) we censored follow-up at the time of ART initiation to better appreciate the association between HIV-1 DNA and mortality during the period when patients did not receive ART.

The interaction between variables was tested. The assumption of the proportional hazards was examined. Statistical analyses were performed with $\mathrm{SAS}^{\circledR} 9.3$ software.

\subsection{Funder, registration and ethics}

At the end of the 30-month follow-up for the trial, we asked patients to renew their informed consent for participating in the post-trial phase. The Temprano protocol, which included the posttrial phase, was approved by the Côte d'Ivoire National Ethics Committee for Health Research. It was registered at Clinical Trials.gov (NCT00495651). The sponsor (Agence Nationale de Recherches sur le Sida et les hépatites virales) had no role in the conduct of the study and interpretation of the data.

\section{Results}

\subsection{Baseline and follow-up characteristics}

Between March 2008 and July 2012, 2076 patients were included in Temprano and randomly assigned to start ART immediately $(N=1041)$ or to defer ART until the WHO criteria for starting ART

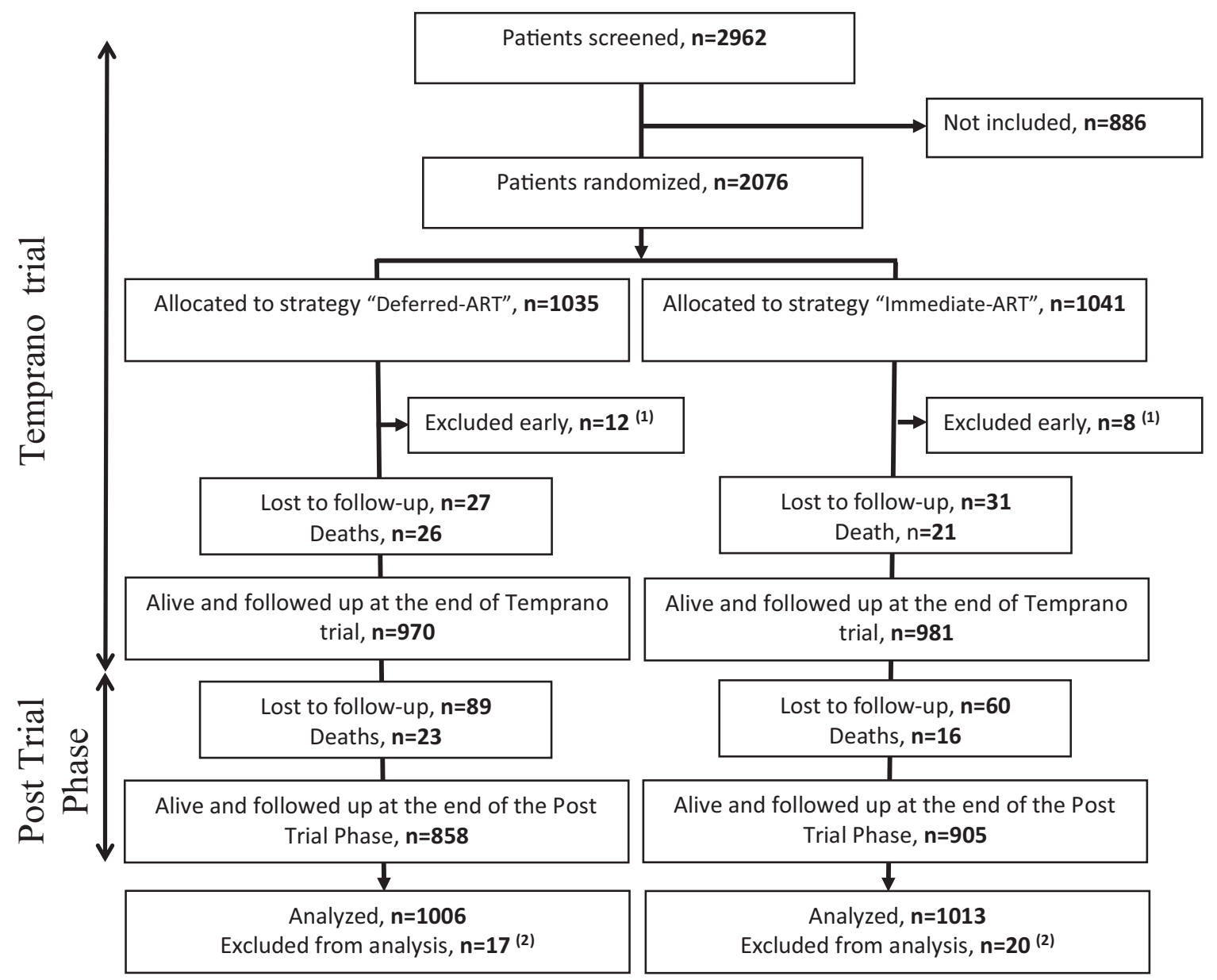

Fig. 1. Temprano trial and post-trial Flow Chart.

[1] 20 patients who underwent randomization were excluded early (see detail in Reference 10)

[2] These patients were alive and followed up at the end of Temprano long term follow-up but were excluded from analysis for the present paper because they had missing HIV1 DNA values at baseline. 
were met $(N=1035) .20(1 \%)$ were subsequently excluded and 2056 were included in the Temprano analysis at 30 months. All participants who were still alive and followed up at 30 months agreed to participate in the post-trial phase. Of the 2056 patients included in the Temprano analysis, 37 (1.8\%) were further excluded because of missing HIV-1 DNA value at baseline, and 2019 were included in the present analysis (Fig. 1).

Baseline and follow-up characteristics of the 2019 patients are shown in Table 1.

The 2019 participants were followed for a total 9253 personyears, including 4674 during the trial and 4579 during the post-trial phase. The median follow-up time was 4.9 years overall (Interquartile Range [IQR] 3.4 - 5.8). Of the 2019 patients, 1601 (79\%) ever started ART, including: 1013 who were randomized in the immediate ART Temprano strategy and therefore started ART at inclusion; and 588 who were randomized in the deferred ART strategy and later met the most recent WHO starting criteria during follow-up.

Baseline HIV-1 RNA and HIV-1 DNA levels were significantly correlated (Spearman's correlation: $R=0.59 ; p<0.0001$ ) (Fig. 2). At the

Table 1

Baseline and follow up characteristics $(n=2019)$.

\begin{tabular}{|c|c|}
\hline Baseline & \\
\hline Age, years, median (IQR) & $35(30-42)$ \\
\hline Sex, female, $\mathrm{n}(\%)$ & $1584(78)$ \\
\hline \multicolumn{2}{|l|}{ Randomized to, n (\%) } \\
\hline Deferred ART & $1006(49.8)$ \\
\hline Early ART & $1013(50.2)$ \\
\hline WHO clinical stage 1 or $2, \mathrm{n}(\%)$ & $1822(90)$ \\
\hline \multicolumn{2}{|l|}{$\mathrm{CD} 4$ cell count $/ \mathrm{mm}^{3}$} \\
\hline Median (IQR) & $462(368-571)$ \\
\hline \multicolumn{2}{|l|}{ Categories, n (\%) } \\
\hline$<350$ & $423(21)$ \\
\hline $350-499$ & $770(38)$ \\
\hline$\geq 500$ & $826(41)$ \\
\hline \multicolumn{2}{|l|}{ Plasma HIV-1 RNA, $\log _{10}$ copies/ml } \\
\hline Median (IQR) & $4.7(4.0-5.2)$ \\
\hline \multicolumn{2}{|l|}{ Categories, $\mathrm{n}(\%)^{*}$} \\
\hline$<5 \log _{10}$ copies $/ \mathrm{ml}$ & $1315(65)$ \\
\hline$\geq 5 \log _{10}$ copies $/ \mathrm{ml}$ & $699(35)$ \\
\hline \multicolumn{2}{|c|}{ PBMCs HIV-1 DNA, $\log _{10}$ copies $/ 10^{6}$} \\
\hline Median (IQR) & $2.9(2.5-3.3)$ \\
\hline \multicolumn{2}{|l|}{ Categories, n (\%) } \\
\hline$<3 \log _{10}$ copies $/ 10^{6}$ & $1089(54)$ \\
\hline$\geq 3 \log _{10}$ copies $/ 10^{6}$ & $930(46)$ \\
\hline
\end{tabular}

\section{Follow-up}

\begin{tabular}{cl}
\hline Ever started ART, $\mathrm{n}(\%)$ & $1601(79)$ \\
First-line regimen, $\mathrm{n}(\%)$ & $1113(70)$ \\
TDF-FTC plus EFV & $372(23)$ \\
TDF-FTC plus LPV/r & $116(7)$ \\
Other ${ }^{\text {S }}$ & \\
Duration of follow up, patient-years & 9253 \\
Overall follow-up & 4674 \\
Temprano trial & 4579 \\
Post Trial Phase & \\
Lost to follow-up, n (\%) & $206(10.2)$ \\
Overall follow-up & $57(2.8)$ \\
Temprano trial & $149(7.4)$ \\
Post Trial Phase & \\
Death, n (\%) & $86(4.3)$ \\
Overall follow-up & $47(2.3)$ \\
Temprano trial & $39(1.9)$ \\
Post Trial Phase
\end{tabular}

IQR: Interquartile range: WHO: World Health Organization ; ART: Antiretroviral Therapy; TDF: tenofovir; FTC: emtricitabine; ZDV: zidovudine; LPV/r: Lopinavir/ritonavir; PBMC: Peripheral Blood Mononuclear Cells; DNA: deoxyribonucleic acid; RNA: ribonucleic acid; $\S$ Other regimens were: TDF-FTC-ZDV $(n=80)$; ZDV-3TC-LPV/r $(n=25)$; ZDV-3TC-EFV $(n=3)$; ZDV-3TC-nevirapine $(n=3)$; didanosine-3TC-EFV $(n=1)$; stavudine-3TC-EFV $(n=1)$; stavudine-3TC-LPV/r $(n=1)$; 3TC-abacavir-LPV/r ( $n=1)$; TDF-FTC-stavudine $(n=1) ;{ }^{*} N=2014$ (5 missing values). end of the post trial phase, 206/2019 (10.2\%) patients were lost to follow-up, including 106/1089 (9.7\%) patients with baseline PBMC HIV1 DNA $<3$ and 100/930 (10.8\%) with baseline PBMC HIV-1 DNA $\geq 3$ $\log _{10}$ copies $/ 10^{6}$ cells.

\subsection{HIV-1 DNA and risk of death}

During follow-up, 86 deaths were recorded. The percentage of deaths increased with increasing baseline PBMC HIV-1 DNA value. The number and percentage of death among the total number of patients having a baseline HIV-1 DNA $<2,2 \leq$ DNA $<2.5,2.5 \leq$ DNA $<3,2.5 \leq \mathrm{DNA}<3$ and DNA $\geq 3.5 \log _{10}$ copies $/ 10^{6}$ PBMC was $3 / 183$ (1.6\%), 6/311 (1.9\%), 17/595 (2.9\%), 35/665 (5.3\%), and 25/265 (9.4\%), respectively.

The incidence of death was 1.40 per 100 person-years in patients with baseline HIV-1 DNA $\geq 3$ and 0.52 per 100 person-years in patients with baseline HIV-1 DNA $<3 \log _{10}$ copies $/ 10^{6}$ PBMC. The 6year probability of death was $7.9 \%(95 \% \mathrm{CI} 6.1-10.3)$ in patients with baseline HIV-1 DNA $\geq 3$ and 3.4\% (95\% CI 2.2-5.2) in patients with baseline HIV-1 DNA $<3$ (Fig. 3a). The median time to death was 40.3 months (IQR 27.0-53.4) in patients with baseline HIV-1 DNA $<3$ $\log _{10}$ copies $/ 10^{6}$ PBMC and 23.6 months $(7.9-40.2)$ in those with HIV-1 DNA $\geq 3 \log _{10}$ copies $/ 10^{6}$ PBMC.

The Hazard Ratio of death for patients with baseline HIV-1 DNA $\geq 3$ compared to baseline HIV-1 DNA $<3$ was 2.67 (95\% CI $1.68-4.22$ ) in univariate analysis, and 2.09 (95\% CI 1.24-3.52) in multivariate analysis adjusted for the ART strategy, IPT, trial center, baseline CD4 count, sex, age and plasma HIV-1 RNA. Other factors significantly associated with death were IPT and plasma HIV-1 RNA in univariate analysis. In multivariate analysis, the risk of death remained significantly higher in patients with no IPT, but was no longer significantly associated with baseline plasma HIV-1 RNA (Table 2).

Fig. 3b shows the probability of death over time by groups of HIV1 DNA and HIV-1 RNA. The 6-year probability of death was $7.7 \%$ in patients with HIV-1 DNA $\geq 3$ and HIV-1 RNA $\geq 5,5.3 \%$ in patients with HIV-1 DNA $\geq 3$ and HIV-1 RNA $<5,4.3 \%$ in patients with HIV-1 DNA $<3$ and HIV- 1 RNA $\geq 5$, and $2.3 \%$ in patients with HIV-1 DNA $<3$ and HIV-1 RNA $<5$.

Fig. 3c shows the probability of death over time by groups of HIV-1 DNA and Temprano ART strategy. The 6-year probability of death was $8.8 \%$ in patients randomized to deferred ART with HIV-1 DNA $\geq 3,3.4 \%$ in patients randomized to deferred ART with HIV-1 DNA $<3,6.9 \%$ in patients randomized to early ART with HIV-1 DNA $\geq 3$, and $3.4 \%$ in patients randomized to early ART with HIV-1 DNA $<3$.

Of the 86 deaths, 56 were considered to be of unknown cause. In the case of 30 deaths, a possible or probable cause was identified (Table SA1 in the Supplemental Appendix). The percentage of deaths with identified causes was similar in patients baseline HIV-1 DNA $\geq 3$ $\log _{10}$ copies $/ 10^{6}$ PBMC and in those with HIV-1 DNA $<3(21 / 60$ [35\%] vs. $9 / 26$ [35\%], $p=0.97$ ). In patients who started ART, the last available plasma viral load was more frequently detectable in patients with baseline HIV-1 DNA $\geq 3$ ( $23 \%$ vs. $18 \%$ ); and the percentage of patients who died among those with detectable viral load tended to be higher in patients with baseline HIV-1 DNA $\geq 3$ (7\% vs. 3\%)(Table SA2 in the Supplemental Appendix).

\subsection{Sensitivity analysis}

The Hazard Ratios of patients with HIV-1 DNA $\geq 3$ compared to $<3$ and patients with HIV-1 RNA $\geq 5$ compared to $<5$ remained similar in univariate and multivariate analysis when the Temprano ART strategy was replaced with actual ART initiation and when censoring follow-up at ART initiation (Table 2). 


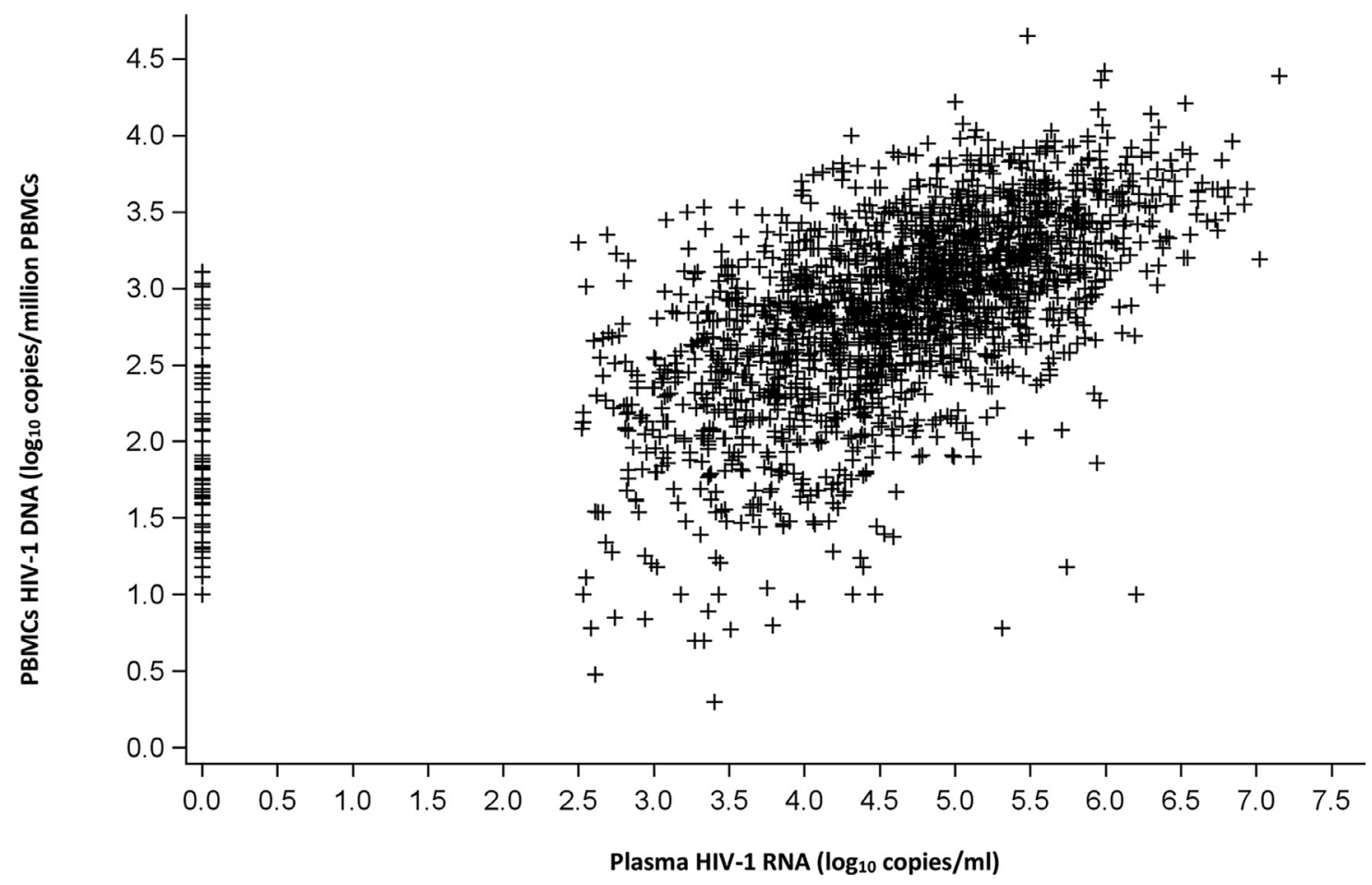

Fig. 2. Spearman's correlation between plasma HIV-1 RNA and PBMC HIV-1 DNA levels $(N=2014)$.

PBMC: Peripheral Blood Mononuclear Cells; DNA: deoxyribonucleic acid; RNA: ribonucleic acid; Spearman's correlation coefficient: $R=0.59, p<0.0001$.

\section{Discussion}

We analyzed the association between HIV-1 DNA in PBMC and medium-term mortality in African adults who started ART early, in a country were patients are mainly infected with HIV-1 non B subtypes.

We found that patients with high HIV-1 DNA level at baseline had a higher 6-year mortality risk than other patients, irrespective of plasma viral load, CD4 cell count and ART.

To the best of our knowledge, this is the first study to report this association. Previous cohort studies conducted in industrialized countries with shorter follow-ups have shown that high DNA levels are closely associated with the prognosis, using an outcome combining severe morbidity, mortality and CD4 cell count evolution [3,8,9,15-17]. In previous studies, a low level of pre-therapeutic HIV1 DNA was also associated with the virological success of ART [7,18-21].

The distribution of HIV-1 DNA levels in our patients was very similar to the one we previously measured in a cohort of recentlyinfected adults in Abidjan in the 1990s [15,16]. This is consistent with the long-acknowledged notion that the reservoir is established very early in infection and varies little thereafter [22].

Our findings help put into perspective the practical utility of cellular HIV-1 DNA and plasma HIV-1 RNA in clinical monitoring. Baseline HIV-1 DNA and RNA levels were significantly but moderately correlated, suggesting a different role for these two markers in the pathophysiology of HIV-1 infection. The association observed in univariate analysis between pre-therapeutic plasma HIV-1 RNA and mortality was quashed by the effect of cellular HIV-1 DNA in multivariate analysis, which suggests that infected cells play a major role in the progression of the disease. Therefore, with regard to pre-therapeutic markers, HIV-1 DNA seems to be a better predictor of the long-term prognosis. In terms of on-treatment markers though, HIV-RNA is the gold standard for monitoring ART efficacy. Under effective ART, plasma HIV-1 RNA becomes undetectable while cellular HIV-1 DNA decreases slightly but remains at a level close to the pre-therapeutic level [23]. For HIV-1 DNA to become a useful marker for treatment monitoring and comparing treatment strategies in research, we would need powerful new treatments for HIV with effective reservoir action [24].

In our study, both early-ART and actual ART initiation tended to reduce the risk of death compared to deferred-ART, but this did not reach significance. This may be due to a lack of power. Our study was supported by a large sample size and a long follow-up period. Our findings were robust in sensitivity analyses. However, there were also several limitations.

Firstly, the association of a marker with the prognosis in a cohort study must be interpreted with caution, as there is always the possibility of one or several confounding factors unrecorded in the database.

Secondly, while we reported the rate of severe morbidity events at 30 months in the initial Temprano paper, long-term morbidity data is not reported in the present paper. During the trial phase, the Event Documentation Committee used standardized criteria to validate and classify all severe morbidity events. These criteria were a combination of clinical definitions and laboratory and radiological test results. Some clinical definitions included evolution under standardized care and treatment [10]. During the post-trial phase, participants had to pay for tests other than routine ART monitoring tests, and for care and treatment other than ART. Therefore, we did not document morbidity events during the PTP but focused our efforts on documenting mortality.

In conclusion, the reservoir of HIV-1 continues to play a key role in the prognosis in patients who start ART early, regardless of plasma viral load. Cellular HIV-1 DNA is an interesting clinical marker for use in future research. At present, the pre-therapeutic level of DNA can be used as a predictor of treatment success. Since HIV-1 DNA does not decrease significantly on ART, measuring DNA in patients on ART would currently not be of much use on a routine basis. However, if new treatments were to have the effect of reducing the reservoir in 

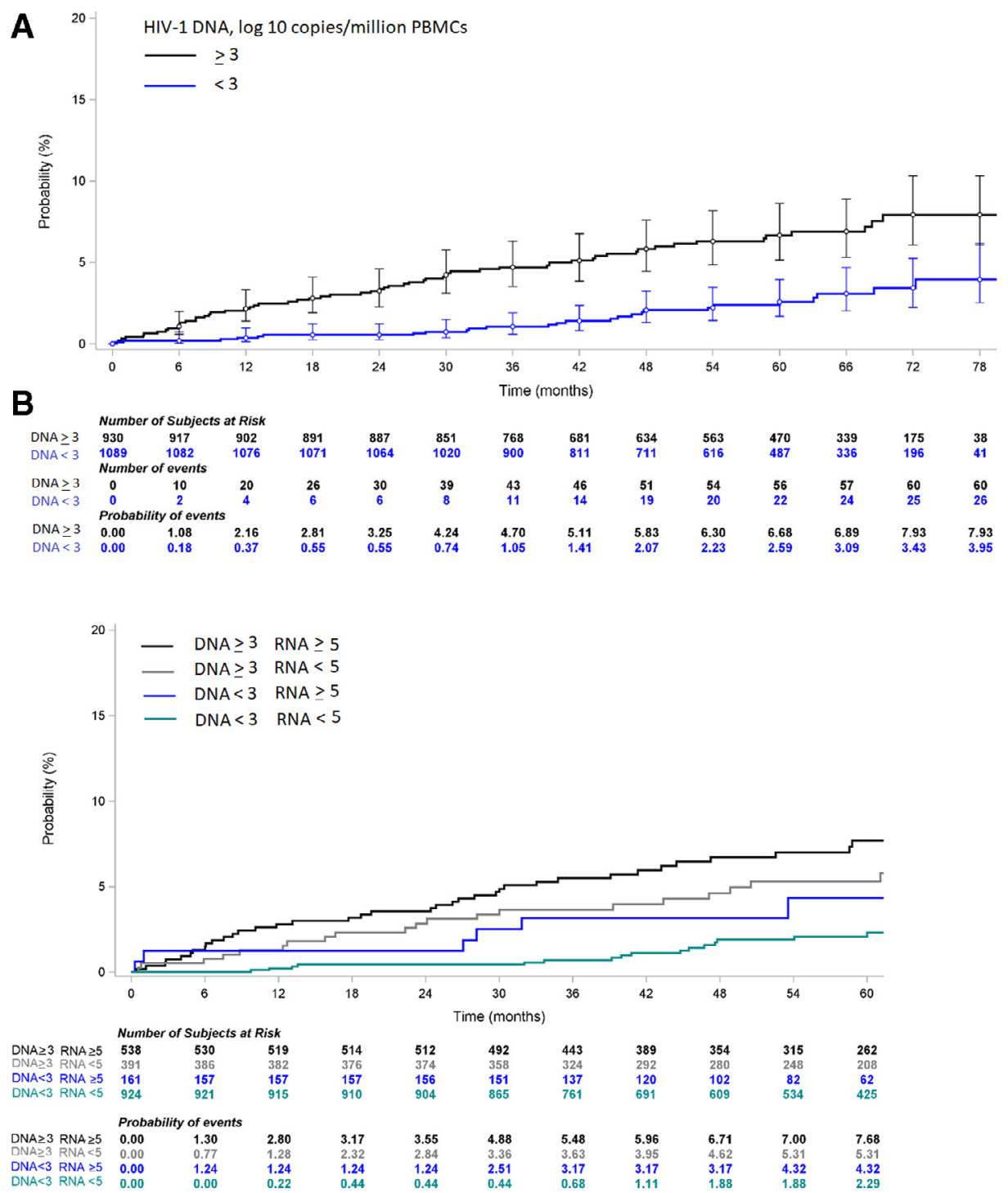

C

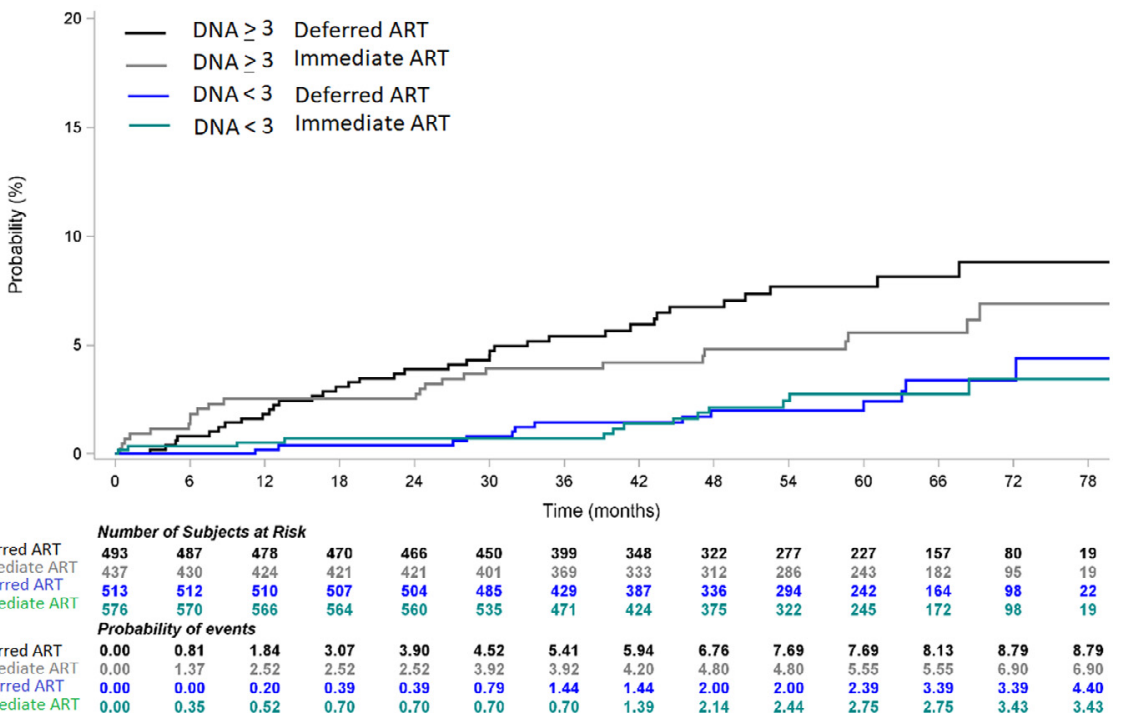

Fig. 3. (a) Kaplan Meier curve of probability of death, by baseline PBMC HIV-1 DNA level $(N=2019)$.

PBMC: Peripheral Blood Mononuclear Cells; DNA: deoxyribonucleic acid; RNA: ribonucleic acid; Log-rank: $p<0.0001$.

(b) Kaplan Meier curve of probability of death, by baseline PBMC HIV-1 DNA level and baseline plasma HIV-1 RNA level $(N=2014)$.

PBMC: Peripheral Blood Mononuclear Cells; DNA: deoxyribonucleic acid; RNA: ribonucleic acid; Log-rank: $p<0.0001$.

(c) Kaplan Meier curve of probability of death, by baseline PBMC HIV-1 DNA level and Temprano ART strategy $(N=2019)$.

PBMC: Peripheral Blood Mononuclear Cells; DNA: deoxyribonucleic acid; ART: Antiretroviral Therapy; Log-rank: $p<0.0001$. 
Table 2

Baseline characteristics associated with the risk of death.

\begin{tabular}{|c|c|c|c|c|c|c|}
\hline & \multicolumn{3}{|c|}{ Univariate analysis } & \multicolumn{3}{|c|}{ Multivariate analysis $(N=2014)$} \\
\hline & HR & $95 \%$ IC & $p$ & aHR & $95 \%$ IC & $p$ \\
\hline ART strategy: early $v$ s. deferred & 0.74 & $0.48-1.13$ & 0.17 & 0.76 & $0.49-1.16$ & 0.20 \\
\hline IPT strategy: yes vs. no & 0.64 & $0.41-0.98$ & 0.04 & 0.63 & $0.41-0.97$ & 0.03 \\
\hline Sex: Male vs. female & 1.50 & $0.94-2.39$ & 0.08 & 1.39 & $0.86-2.24$ & 0.17 \\
\hline Plasma HIV-1 RNA: $\geq 5$ vs. $<5 \log _{10}$ copies/ml & 2.10 & $1.38-3.21$ & 0.0006 & 1.44 & $0.90-2.32$ & 0.13 \\
\hline PBMC HIV-1 DNA: $\geq 3$ vs. $<3 \log _{10}$ copies $/ 10^{6}$ cells & 2.67 & $1.68-4.22$ & $<0.0001$ & 2.09 & $1.24-3.52$ & 0.005 \\
\hline CD4+ cell count: & & & 0.18 & & & 0.31 \\
\hline $350-500$ vs. $<350$ cells $/ \mathrm{mm}^{3}$ & 0.90 & $0.54-1.48$ & 0.67 & 0.99 & $0.59-1.64$ & 0.96 \\
\hline$\geq 500$ vs. $<350$ cells $/ \mathrm{mm}^{3}$ & 0.60 & $0.34-1.06$ & 0.08 & 0.68 & $0.37-1.21$ & 0.19 \\
\hline
\end{tabular}

\begin{tabular}{|c|c|c|c|c|c|c|}
\hline & \multicolumn{3}{|c|}{ Univariate analysis* } & \multicolumn{3}{|c|}{ Multivariate analysis $* N=2014$} \\
\hline & HR & $95 \%$ IC & $p$ & aHR & $95 \%$ IC & $p$ \\
\hline ART really started ${ }^{1}$ & 0.91 & $0.54-1.52$ & 0.71 & 0.78 & $0.46-1.34$ & 0.37 \\
\hline IPT strategy: yes vs. no & 0.64 & $0.41-0.98$ & 0.04 & 0.63 & $0.41-0.97$ & 0.04 \\
\hline Sex: Male vs. female & 1.50 & $0.94-2.39$ & 0.08 & 1.39 & $0.86-2.24$ & 0.18 \\
\hline Plasma HIV-1 RNA: $\geq 5$ vs. $<5 \log _{10}$ copies $/ \mathrm{ml}$ & 2.10 & $1.38-3.21$ & 0.0006 & 1.44 & $0.89-2.32$ & 0.13 \\
\hline PBMC HIV-1 DNA: $\geq 3$ vs. $<3 \log _{10}$ copies $/ 10^{6}$ cells & 2.67 & $1.68-4.22$ & $<0.0001$ & 2.12 & $1.26-3.57$ & 0.005 \\
\hline CD4+ cell count: & & & 0.18 & & & 0.26 \\
\hline $350-500$ vs. $<350$ cells $/ \mathrm{mm}^{3}$ & 0.90 & $0.54-1.48$ & 0.67 & 0.97 & $0.58-1.61$ & 0.89 \\
\hline$\geq 500$ vs. $<350$ cells $/ \mathrm{mm}^{3}$ & 0.60 & $0.34-1.06$ & 0.08 & 0.64 & $0.36-1.17$ & 0.15 \\
\hline
\end{tabular}

Characteristics associated with the risk of death, sensitivity analysis $\mathrm{N}^{\circ} 2$ : patients randomized to deferred ART strategy with follow-up censored at ART initiation Univariate analysis*

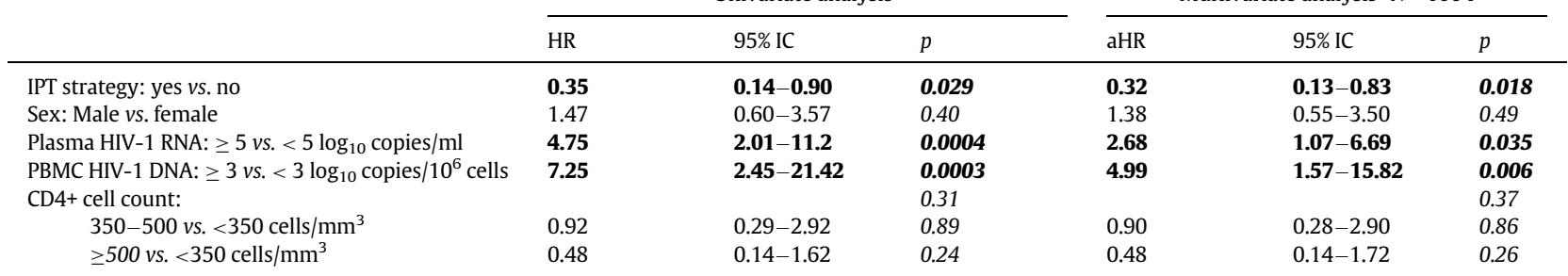

$\mathrm{N}$ : number of patient; HR : Hazard ratio; aHR : adjusted Hazard ratio (Adjusted for study centre and for all other variables shown in the table); ART: antiretroviral treatment; IPT : Isoniazid preventive therapy; CI: confidence interval; PBMC: Peripheral Blood Mononuclear Cells; DNA: deoxyribonucleic acid; RNA: ribonucleic acid. ${ }^{*}$ Cox proportional hazards models; $\mathrm{N}$ : number of patient; aHR : adjusted Hazard ratio (adjusted for study centre and for all other characteristics shown in the table); IPT : Isoniazid preventive therapy; CI: confidence interval: PBMC: Peripheral Blood Mononuclear Cells; DNA: deoxyribonucleic acid; RNA: ribonucleic acid; (1): ART was started $v$ s. ART was never started (time dependant variable) during trial and post-trial follow-up.

${ }^{*}$ Cox proportional hazards models ; $\mathrm{N}$ : number of patient; aHR : adjusted Hazard ratio (adjusted for study centre and for all other characteristics shown in the table);

IPT: Isoniazid preventive therapy; CI: confidence interval: PBMC: Peripheral Blood Mononuclear Cells; DNA: deoxyribonucleic acid; RNA: ribonucleic acid.

the future, the evolution of HIV-1 DNA under treatment would become an important marker for evaluating the effectiveness of these new treatments.

\section{Declaration of Competing Interest}

All authors report no conflict of interest.

\section{Acknowledgments}

We are indebted to all patients who participated in this trial.

We also gratefully acknowledge the valuable contributions of the SMIT, CeDReS, CePReF, CMSDS, HGAN, CIRBA, USAC, FSU Com Anonkoua-Kouté, Hôpital El Rapha, centre La Pierre Angulaire, PACCI, PNLS, PNLT, NPSP, CEPAC international, RIP plus and INSERM 1219 teams.

We thank Merck Sharp \& Dohme, for the donation of Stocrin ${ }^{\circledR}$ and Gilead Sciences, for the donation of Truvada ${ }^{\circledR}$ for all participants in the study; The 'Nouvelle Pharmacie de Santé Publique' of Côte d'Ivoire, for providing all others antiretroviral drugs; and The President's Emergency Plan for AIDS Relief (PEPFAR) for supporting the 'Nouvelle Pharmacie de Santé Publique' of Côte d'Ivoire in antiretroviral drugs supply

\section{Supplementary materials}

Supplementary material associated with this article can be found in the online version at doi:10.1016/j.ebiom.2020.102815.

\section{References}

[1] Sharaf RR, Li JZ. The alphabet soup of HIV reservoir markers. Curr HIV/AIDS Rep 2017;14(2):72-81.

[2] Kimata JT, Rice AP, Wang J. Challenges and strategies for the eradication of the HIV reservoir. Curr Opin Immunol 2016;42:65-70.

[3] Avettand-Fènoël V, Hocqueloux L, Ghosn J, Cheret A, Frange P, Melard A, et al. Total HIV-1 DNA, a marker of viral reservoir dynamics with clinical implications. Clin Microbiol Rev 2016;29(4):859-80.

4] Alidjinou EK, Bocket L, Hober D. Quantification of viral DNA during HIV-1 infection: a review of relevant clinical uses and laboratory methods. Pathol Biol. 2015;63(1):53-9.

[5] Rouzioux C, Avettand-Fenoël V. Total HIV DNA: a global marker of HIV persistence. Retrovirology 2018:15(1):30.

[6] Parisi SG, Andreis S, Mengoli C, Scaggiante R, Ferretto R, Manfrin V, et al. Baseline cellular HIV DNA load predicts HIV DNA decline and residual HIV plasma levels during effective antiretroviral therapy. J Clin Microbiol. 2012;50(2):258-63.

[7] Masquelier B, Taieb A, Reigadas S, Marchou B, Cheneau C, Spire B, et al. Cellular HIV-1 DNA quantification and short-term and long-term response to antiretroviral therapy. J Antimicrob Chemother 2011;66(7):1582-9.

[8] Williams JP, Hurst J, Stöhr W, Robinson N, Brown H, Fisher M, et al. HIV-1 DNA predicts disease progression and post-treatment virological control. Elife 2014;3:e03821.

[9] Tsiara CG, Nikolopoulos GK, Bagos PG, Goujard C, Katzenstein TL, Minga AK, et al. mpact of HIV type 1 DNA levels on spontaneous disease progression: a metaanalysis. AIDS Res Hum Retroviruses 2012;28(4):366-73. 
[10] TEMPRANO ANRS 12136 Study Group, Danel C, Moh R, Gabillard D, Badje A, Le Carrou J, et al. A Trial of early antiretrovirals and isoniazid preventive therapy in Africa. N Engl J Med 2015;373(9):808-22.

[11] INSIGHT START Study Group, Lundgren JD, Babiker AG, Gordin F, Emery S, Grund $\mathrm{B}$, et al. Initiation of antiretroviral therapy in early asymptomatic HIV infection. N Engl J Med. 2015;373(9):795-807.

[12] World Health Organization, World Health Organization, Department of HIV/AIDS. Guideline on when to start antiretroviral therapy and on pre-exposure prophylaxis for HIV. [Internet]. 2015 [cited 2019 Sep 4]. Available from: http://www. ncbi.nlm.nih.gov/books/NBK327115/.

[13] Badje A, Moh R, Gabillard D, Guéhi C, Kabran M, Ntakpé J-B, et al. Effect of isoniazid preventive therapy on risk of death in west African, HIV-infected adults with high CD4 cell counts: long-term follow-up of the Temprano ANRS 12136 trial. Lancet Glob Health 2017;5(11):e1080-9.

[14] Rouet F, Chaix M-L, Nerrienet E, Ngo-Giang-Huong N, Plantier J-C, Burgard M, et al. Impact of HIV-1 genetic diversity on plasma HIV-1 RNA quantification: usefulness of the Agence Nationale de Recherches sur le SIDA second-generation long terminal repeat-based real-time reverse transcriptase polymerase chain reaction test. J Acquir Immune Defic Syndr 2007;45(4):380-8.

[15] Minga AK, Anglaret X, d' Aquin Toni T, Chaix M-L, Dohoun L, Abo Y, et al. HIV-1 DNA in peripheral blood mononuclear cells is strongly associated with HIV-1 disease progression in recently infected West African adults. J Acquir Immune Defic Syndr 2008;48(3):350-4.

[16] Rouzioux C, Hubert J-B, Burgard M, Deveau C, Goujard C, Bary M, et al. Early levels of HIV-1 DNA in peripheral blood mononuclear cells are predictive of disease progression independently of HIV-1 RNA levels and CD4+ T cell counts. J Infect Dis. 2005;192(1):46-55.
[17] Goujard C, Bonarek M, Meyer L, Bonnet F, Chaix M-L, Deveau C, et al. CD4 cell count and HIV DNA level are independent predictors of disease progression after primary HIV type 1 infection in untreated patients. Clin Infect Dis. 2006;42 (5):709-15.

[18] Hatzakis AE, Touloumi G, Pantazis N, Anastassopoulou CG, Katsarou O, Karafoulidou A, et al. Cellular HIV-1 DNA load predicts HIV-RNA rebound and the outcome of highly active antiretroviral therapy. AIDS 2004;18(17):2261-7.

[19] McDermott JL, Giri AA, Martini I, Bono M, Giacomini M, Campelli A, et al Level of human immunodeficiency virus DNA in peripheral blood mononuclear cells correlates with efficacy of antiretroviral therapy. J Clin Microbiol. 1999;37(7):2361-5.

[20] Hoen B, Cooper DA, Lampe FC, Perrin L, Clumeck N, Phillips AN, et al. Predictors of virological outcome and safety in primary HIV type 1-infected patients initiating quadruple antiretroviral therapy: QUEST GW PROB3005. Clin Infect Dis 2007;45 (3):381-90

[21] Tierney C, Lathey JL, Christopherson C, Bettendorf DM, D'Aquila RT, Hammer SM, et al. Prognostic value of baseline human immunodeficiency virus type 1 DNA measurement for disease progression in patients receiving nucleoside therapy. J Infect Dis 2003;187(1):144-8.

[22] Trémeaux P, Rouzioux C, Avettand-Fènoël V. Cell and tissue reservoirs of HIV-1: dynamics during infection. Virologie (Montrouge) 2019;23(4):211-28.

[23] Laanani M, Ghosn J, Essat A, Melard A, Seng R, Gousset M, et al. Impact of the Timing of Initiation of Antiretroviral Therapy During Primary HIV-1 Infection on the Decay of Cell-Associated HIV-DNA. Clin Infect Dis 2015;60 (11):1715-21

[24] Vitoria M, Rangaraj A, Ford N, Doherty M. Current and future priorities for the develoment of optimal HIV drugs. Curr Opin HIV AIDS 2019;14(2):143-6. 